\title{
Manga gástrica y reparación parietal laparoscópica
}

\section{Gastric sleeve and laparoscopic parietal repair}

Nicolás Giroff ${ }^{1}$, Martín Bentancur ${ }^{2}$, Pablo Valsangiacomo³ ${ }^{3}$, Daniel González ${ }^{4}$

DOI: $10.31837 /$ cir.urug/4.2.2

Recibido: 04 de septiembre de 2019

Aceptado: 05 de junio de 2020

\section{Introducción}

El manejo de la hernia ventral en los pacientes sometidos a cirugía bariátrica es controvertido, no existiendo consenso en la literat ura actual sobre el momento óptimo de la reparación de la hernia en relación con el procedimiento bariátrico, así como de la elección del método de reparación herniaria. Cada paciente bariátrico con un defecto de la pared abdominal

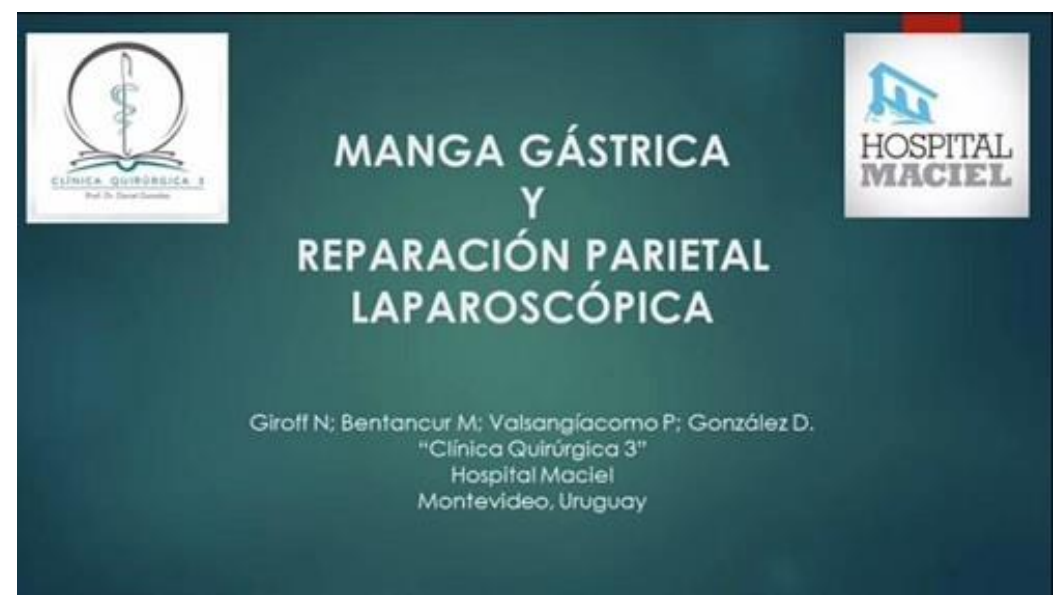
deberá ser abordado individualmente, teniendo en cuenta factores como la presencia de síntomas, tamaño del defecto parietal y la reductibilidad herniaria

Descripción de contenidos: En el video se expone la realización de una manga gástrica laparoscópica en una paciente obesa mórbida con una recidiva de una hernioplastia umbilical. En el mismo acto se lleva a cabo la reparación parietal por vía laparoscópica, destacando el cierre del defecto con puntos de sutura extracorpórea, finalizando con la colocación intraabdominal de una malla compuesta (polyester/colágeno) con un overflap de $5 \mathrm{~cm}$.

1 Residente Cirugía General, Clínica Quirúrgica “3”. Hospital Maciel. Facultad de Medicina, Universidad de la República Montevideo, Uruguay. giroffnicolas@gmail.com

2 Ayudante, Clínica Quirúrgica “3”. Hospital Maciel. Facultad de Medicina, Universidad de la República Montevideo, Uruguay.

3 Profesor Agregado, Clínica Quirúrgica “3”. Hospital Maciel. Facultad de Medicina, Universidad de la República Montevideo, Uruguay.

4 Profesor Titular, Clínica Quirúrgica “3”. Hospital Maciel. Facultad de Medicina, Universidad de la República Montevideo, Uruguay. 